Boise State University

ScholarWorks

$11-1-2013$

\title{
Urban Responses to Climate Change: Theories and Governance Practice in Cities of the Global South
}

Dirk Heinrichs

Institute of Transport Research, German Aerospace Center

Kerstin Krellenberg

Helmholtz Centre for Environmental Research

Michail Fragkias

Boise State University 


\title{
SYMPOSIUM
}

\section{Urban Responses to Climate Change: Theories and Governance Practice in Cities of the Global South}

\author{
DIRK HEINRICHS, KERSTIN KRELLENBERG and \\ MICHAIL FRAGKIAS
}

\begin{abstract}
Cities around the world have recently started to become 'proactive' initiators of climate strategies containing both mitigation and adaptation elements. The experience of these first movers has been studied and documented both empirically and, to a lesser extent, theoretically, primarily for cities in the global North. This symposium addresses related knowledge gaps by exploring case studies of urban regions in the global South confronting their projected climate change challenges, showcasing the experiences of Delhi, Santiago de Chile and Bogotá. Its specific aim is to explore the urban social response to nature change, the adaptation challenges faced by cities across the world and current practices of urban adaptation. Further, the symposium seeks to understand to what extent and in what respect current conceptual frameworks - which highlight urban ecological security and vulnerability - provide a useful context/framing to assist cities in confronting their challenges and to explain their actions. This introductory article examines current knowledge of the theory and practice of urban climate response. It introduces the concepts of ecological security and vulnerability and discusses the adaptive capacity of cities and how they are starting to respond to the emerging challenges of climate change. It concludes with a synthesis of the case articles and highlights some of the findings.
\end{abstract}

\section{The focus of this symposium}

Human ingenuity has brought about major global changes through social and technological processes that became dominant by the middle of the nineteenth century. Progress in the scientific understanding of social-ecological systems has shown that certain environmental outcomes of global change, such as changes in land use and climate change, have brought humanity face to face with potentially insurmountable challenges to an uninterrupted increase in the wellbeing of the human population and the health of the world's ecosystems. Rather remarkably, but discouragingly, while change is still accelerating at a rapid pace leading to the previously unforeseen negative environmental consequences observed over the last 100 years, societal responses have so far been limited. Humankind's realization of this new planetary era and the novel challenges at hand has been slow. The current scientific consensus suggests that we cannot afford to ignore these challenges any more. 
One of the major global changes this article addresses is the global shift from rural to urban living that has been a defining trend of the last 100 years (Seto et al., 2010). Urban areas have increasingly become more important in the world's social, economic, cultural, political and environmental spheres (Sánchez-Rodríguez et al., 2005). Half of the world's population now lives in cities compared to 30\% 50 years ago and $10 \% 100$ years ago. Most of the world's future population growth is projected to occur in the rapidly growing cities of Africa and Asia and to a lesser extent in Latin America (UN Population Division, 2008). Africa and Asia today are urbanizing more quickly and at a larger volume, respectively, than the rest of the world's regions. While projections envisage more megacities (with populations of over 10 million people), they are expected to contain approximately the same proportion of the world's urban population - around $15 \%$ (ibid.). The majority of new growth is expected to occur in medium-sized cities of the developing world.

In parallel, and intricately interwoven with the process of urbanization, anthropogenic global environmental change has been extensively documented and is acknowledged now as reality by the majority of scientists. Global environmental change (GEC) is defined as the set of biophysical transformations of land, oceans and atmosphere, driven by a coupled system of human and natural processes. More formally, GECs are global changes that (1) alter the well-mixed fluid envelopes of the earth system (the atmosphere and the oceans) and hence are experienced globally and (2) occur in discrete sites but are so widespread as to constitute a global change (Vitousek, 1992). Examples of the former include change in the composition of the atmosphere, climate change, decreased stratospheric ozone concentrations and increased ultraviolet input - of the latter, land use change, loss of biological diversity, biological invasions and changes in atmospheric chemistry.

At the forefront of global environmental change realities lie the global warming trends connected with changes in temperature and precipitation patterns, progressive sea level rise, and increased intensity (and maybe frequency) of extreme climatic episodes leading to (natural) disasters (Simon, 2007). It is a fact today that "warming in the climate system is unequivocal' (IPCC 2007a: 30) and that 'most of the observed increase in globally averaged temperatures since the mid-20th century' is very likely due to human activity (ibid.: 38). The globally expected average temperature increases across scenarios suggest impacts that range from mild to catastrophic. Sea-level rise is expected to be close to one metre in the 21st century (ibid.). Additional predictions with regard to natural disasters and extremes of temperature and precipitation, and their extent and frequency, solidify the scientific consensus in favour of the threat of climate change to human security, safety and health in urban areas in the next 100 years. In response to research findings in the last two decades, scientists are asking for deep greenhouse gas (GHG) emission reductions as soon as possible to avoid the most catastrophic consequences of climate change. For this reason, aggressive mitigation strategies are deemed critical for the stabilization of the global climate.

Not only is climate change expected to impact urban areas in a multiplicity of ways through context-dependent stressors, but a specific level of impact is also irreversible under current technological capacities (Solomon et al., 2009). Research suggests that increases in atmospheric temperature due to increased $\mathrm{CO}_{2}$ concentrations are not expected to decrease significantly or only very slowly even if we suddenly shifted to a net zero carbon economy (IPCC, 2007). It is thus not surprising that, while international political discussion and the quest for an effective international environmental agreement continue to centre mostly on GHG emission reductions by world nations, irreversible climate change and its expected short- and long-term effects have recently attracted growing attention to adaptation options. Responding to the new knowledge generated on climate change impacts worldwide, so-called 'world' (or 'global') cities are starting to formulate climate change adaptation plans. Climate change responses, though, are not limited to larger and wealthier urban areas; a multitude of autonomous actions reveal that cities have begun to confront the issue of climate change. 
This symposium addresses knowledge gaps by exploring case studies of urban regions confronting their projected climate change challenges. The contributions examine the concrete climate response of a selection of cities - not limiting this selection to the so-called world cities, but broadening the perspective to include cities in the global South. On the basis of the applied research showcased in this symposium, the aim is, first, to explore how to characterize the urban social response to nature change given the urban governance experience across the globe thus far. Are there new pathways through which urban governance can better address the problem of climate change? Second, to generate a more systematic understanding of the adaptation challenges that cities face across the world and of the current practices of urban adaptation (who does it, how it is prioritized, how it occurs, and in response to what specific stimuli), and also to ascertain whether cities are lacking important adaptive capacity as they attempt to respond to climate change. Third, to ask to what extent and in what respect are current conceptual frameworks that highlight urban ecological security (UES) or vulnerability providing a useful context/framing to assist cities in confronting the challenges? Fourth, to examine how the future viability of current actions or plans can be judged through these conceptual frameworks. How can we evaluate current practice through the lenses of different conceptual frameworks? In the context of these questions, the term 'city' is used in two different ways. On the one hand, it describes a contingent area together with its climatic, ecological and urbanization characteristics and its sensitivity to environmental change. On the other, it refers to the actors, both single and collective, from within and outside the city and from across national, regional and local levels together with their efforts to confront the potentially negative effects that are connected with this change and their strategies to aggregate 'adaptive capacity'.

This introductory article is structured as follows: first, it explores the linkages between concepts of ecological security and vulnerability and the question of how cities are starting to respond to the emerging challenges of climate change. Second, it summarizes current debates on urban action to adapt to, respond to and cope with climate change and explores the concept of 'adaptive capacity'. Third, it introduces the selected case cities. Finally, and returning to the questions outlined above, it synthesizes the case papers and draws conclusions.

\section{Conceptual frameworks for urban responses to climate change}

While climate change appears as the dominant process of ongoing global change, urbanization is providing much of the context for and affecting the potential consequences of a changing climate. Cities are key sources of greenhouse gas emissions due to the concentration, size and range of economic activity within their boundaries and trade involving transportation across their boundaries. Anticipated climate changes in cities add to existing vulnerabilities that they already generate themselves. The wide array of effects, including the increase in resource scarcity and the unequal distribution of (or access to) resources, creates 'stress bundles' that increase the probability of dangerous climate change for urban areas across the world (de Sherbinin et al., 2007).

Consequently, adaptation in cities to climate change is moving into focus as an essential and, complementary to mitigation, integral part of climate policy. Adaptation has been defined in numerous ways and in different disciplines (see e.g. Smit et al., 2000). The IPCC refers to climate change adaptation as the adjustment in structures, practices or processes, in order to respond to changing climate conditions and effects (IPCC, 2001). Other definitions (Tompkins and Adger, 2005) place the issue in a wider frame of global environmental change and societal responses. Dealing with adaptation requires an understanding of the vulnerability of societies and ecosystems to the impacts, of their capacity to respond and of the socioeconomic costs of adapting to climate change (Klein et al., 2007). 
The theoretic and conceptual debate to explain the consequences of and responses to climate change in urban areas has centred on different approaches. This symposium explores two approaches, one with an emphasis on ecological security (Hodson and Marvin, 2009), and the other on vulnerability (O'Brien et al., 2007).

The concept of 'ecological security' centres on the critical relationship between environmental change and human security and its role as a main driver of 'social response'. The concept highlights the fact that climate change connects not only with a range of negative environmental effects (such as sea-level rise and extreme events like storms and floods), but likewise affects the availability of resources (e.g. water and energy) that are critical to sustain the economic and social functions of cities. Increasing resource scarcity is expected to threaten local and regional stability.

This relation between the environment and the security of humans and nature has been the object of much research in recent decades and can be traced back to the early 1970 s (WBGU, 2008). More recently, potential security risks as a consequence of environmental change have also attracted the interest of national and supranational policy, although still in a rather subordinate role (ibid.). Responses to the challenge of ecological security have a protection- and utilization-oriented subcomponent: for instance, the restoration of habitats, the prevention of their loss or the reduction of emissions (Rogers, 1997). Building ecological security requires developing and promoting global policies designed to restore equilibrium among human populations and between human populations and nature (Pirages, 1997).

With the debate on climate change, the issue of ecological security has also entered the urban debate (see Hodson and Marvin, 2009). In the context of urbanization and climate change, processes that are increasingly influencing the functioning of cities and adversely affecting scarce resources, infrastructure 'protection' and economic competitiveness are overlaid with 'new' concerns around energy security, constraints on water resources, the growth of diseases, increased flood risks and multiple aspects of demographic shifts such as migration, ageing populations, etc. (UNEP, 2007). Therefore, the application of the concept of ecological security has led cities in the global North to design strategies for achieving an urban reconfiguration and infrastructure change to secure their ecological and material reproduction. Such strategies appear in a direct connection with the desire of urban pro-growth coalitions to secure the (resources) base for future economic growth. In contrast, cities in the global South simply 'make do' or 'improvise' with their restricted resources and constrained capacity (Hodson and Marvin, 2009: 210).

Clearly, the role of cities as culprits and victims of climate change, the continued role of cities as centres for economic growth and the potential they offer for coordinated action make them a prime scale for ecological security analysis. Applying the urban ecological security concept to the context of urbanization and climate change offers the potential for new adaptation strategies as an essential and integral part of climate policy to prevent future regional and global instabilities. A strong link between this action and the environmental problems facing humanity can be seen when, for example, measures to protect against flooding are taken as a common consequence of increasing extreme weather events like heavy rainfall. Cities, particularly in the global North, undertake large infrastructure measures as a strategic protection against climate change impacts. Furthermore, they take measures to achieve a higher degree of autarchy and selfsufficiency in terms of resource consumption (e.g. decentralized and re-localized energy production). And they begin to develop new global urban agglomerations, e.g. city networks and coalitions that enable them to pool their buying power, share best practice and deploy common measurement tools while, so far, responses in the global South are more episodic and less strategic and integrative as economic resources are often limited and ecological security is not at the forefront of the political agenda. Furthermore, the 'goods' and 'bads' of climate change are not distributed evenly across the urban population of the global North and the global South. Poorer nations, cities and their populations are reported to be far more vulnerable to environmental change and to have 
far less capacity to protect themselves from its effects. Therefore, ecological security may not always be the leading concept guiding adaptation action in cities but may rather compete or interlink with concepts that are related to the vulnerability of systems and people.

The IPCC (2007b: 6) defines vulnerability as 'the degree to which a system is susceptible to, and unable to cope with, adverse effects of climate change, including climate variability and extremes. Vulnerability is a function of the character, magnitude and rate of climate change and variation to which a system is exposed, the sensitivity and adaptive capacity of that system'. This means that a system is vulnerable if it is exposed to climate change impacts, if it is sensitive to those impacts, and if it has a low capacity to cope with those impacts (Adger et al., 2005). The emphasis of this concept is clearly on the natural system and it takes into account the adverse effects of climate change that increase the 'probability' of a dangerous exposure of systems and sectors. This approach is referred to subsequently as 'outcome vulnerability' (O'Brien et al., 2007). It follows a 'classic risk assessment approach' and intends to quantify climate change impacts and the assessment of related risks. It considers vulnerability as the 'end point' of a sequence of analyses and follows a top-down perspective.

Adopting this outcome vulnerability approach to cities and responding with adaptive governance action is often based on risk assessments framed by natural science in an attempt to reduce the vulnerability of natural and human systems to actual or expected climate change effects. Vulnerability assessments are most commonly driven by downscaling climate models to the regional level. In general, they are more dedicated to mitigation rather than adaptation measures.

A second vulnerability approach is subsequently referred to as 'contextual vulnerability' (Kelly and Adger, 2000; O'Brien et al., 2007). It considers vulnerability as it emerged in the hazard and disaster community (see e.g. Wisner et al., 1994) and in development studies (in particular livelihood and poverty research; see e.g. Chambers, 1989; McCarney, 2009). In this context, climate-change-related vulnerability adds to already existing vulnerabilities that are structural in nature, often linked to poverty and inequality. The focus is on resources and capacities to prepare for, cope with and adapt to hazards and disasters (Chambers, 1989). Vulnerability is considered to be influenced not only by changing biophysical conditions, but by dynamic social, economic, political, institutional and technological structures and processes. The approach follows a bottom-up perspective and considers how different societal groups are vulnerable to and adapt to climate change. The contextual vulnerability framing on human security rather than ecological security or natural science sets much wider boundaries around the issue of climate change and brings it into the context of 'equity'.

Conceptualizing the contextual vulnerability approach to cities includes the consideration of all 'elements' that are exposed to a hazard or a disaster: humans, social groups, economic sectors, regions within the city or within a country (e.g. coastal zone areas), buildings, the urban infrastructure, etc., as well as the assessment of their ability to cope with the consequences. The contextual vulnerability approach therefore considers vulnerability as a starting point for the development of adaptation strategies.

\section{Urban responses to climate change: capacity and experiences}

Across all world regions, local actors are taking steps in cities to adapt to climate change of various degrees and intensities (Berrang-Ford et al., 2010), as a response to national action plans or as autonomous action. While the observed proliferation of dedicated urban responses to climate change is a rather recent phenomenon, the topic is not entirely new. Since the beginning of the 1990s local governments and other urban actors have been taking initiatives to adjust structures, practices or processes in order to respond to changing climate conditions and effects. In a recent review on cities and climate change 
governance, Bulkeley (2010: 2.21) distinguishes two phases of urban responses to climate change. In a first phase, she argues, pioneering local governments predominantly in the global North launched concrete local policy initiatives to reduce consumption of environmental resources, in particular, energy. The second phase has occurred since the early 2000s and is more political in nature and embraces a much wider array of climate issues that are no longer solely connected to the discourse of sustainability but increasingly sensitive to concerns like risk and vulnerability as well. This second round has witnessed a rapid expansion in terms of the numbers of cities involved, accompanied by a growing diversity in terms of their geographic location, size and position in the functional hierarchy of cities. As discussed above, this wave is also connected to the emergence of city networks as powerful collective actors and the mobilization of private actors (Hodson and Marvin, 2009).

As city governments around the world increasingly put climate change on their agenda, the number of studies that analyse these efforts likewise grows. Results and insights have been presented and discussed at a range of conferences (World Bank Symposium 'Cities and Climate Change' in June 2009; International Conference on Urbanization and Global Environmental Change (UGEC) in October 2010; ICLEI 'Resilient Cities' conferences in May 2010, 2011 and 2012; most recently, the 'Planet under Pressure' conference in March 2012). The wealth of knowledge in these studies permits us to draw a few more general observations. One is that quite a number of studies focus on 'adaptive capacity' to explain how local governance of climate change is falling into place and to identify successes and failures. The term describes the potential of a system, a region or a community to adjust to the effects and consequences of climate change, including climate variability and extremes (Smit and Wandel, 2006). Adaptive capacity characterizes the ability to either prepare for the risks and opportunities related to climate change (proactive adaptation) or to cope with or adjust to potential and actual negative effects (reactive adaptation). It is closely related to the concept of coping capacity. While the latter rather describes the ability to deal directly with extreme events, 'adaptive capacity' describes longer-term time frames, thus implying related learning processes (Yohe, 2001).

The use of adaptive capacity to climate change relates to older and originally not explicitly climate-change-related conceptualizations that use the term 'capacity' with the meaning ability or talent, power or potential (Allen, 2002) and as an umbrella term for referring to a broad set of resources (skills, competences and social relations) possessed by an individual or a social entity such as a group, a community or a society. Most often the term 'capacity' appears in the context of vulnerability and development policy research. In a number of different conceptual approaches, capacity - here referred to as response, coping or adaptive capacity - is considered to be a dimension or component of vulnerability. One of the earliest sustained definitions of vulnerability is provided by Chambers who emphasizes 'capacity' as one component of the double-sided character of vulnerability that links it to exposure to the particular stresses of events: 'Vulnerability has two sides: an external side of risks, shocks and stress to which an individual or household is subject; and an internal side which is defencelessness, meaning a lack of means to cope with damaging losses' (Chambers, 1989: 38). In this definition, vulnerability is determined by the presence (or rather absence) of a set of assets or resources (political, physical, natural, social, financial) that enable an individual, a group, etc. to come to terms with an 'external' stress or damaging event. An alternative perspective understands vulnerability and capacity rather as separate (analytical) entities (Bollin and Hidajat, 2006). This perspective, which is common in disaster risk research and management practice, does not directly relate capacity to a particular stress or event, but takes it more independently. By this definition, capacity is the more general ability (e.g. physical planning capacity, management capacity) to, for instance, confront disasters or reduce risks (UN/ISDR, 2006). Yet another related perspective is the concept of capability (Sen, 1992). It provides a framework to analyse a variety of social issues, such as wellbeing and poverty, liberty and freedom, development, gender bias and 
inequalities, justice and social ethics (ibid). This approach is much wider as it links individual capability with societal concerns of social equity and justice.

As the recent literature on climate change shows, the elements that drive local action - and may also explain its potential success - fall broadly into three aspects of local adaptive capacity: ability, willingness and an enabling/disabling context (Yohe, 2001; Haddad, 2005; Tompkins and Adger, 2005; Burch and Robinson, 2007; Zahran et al., 2008).

Broadly speaking, ability encompasses the 'resources' that put city managers in the position to take action. In this sense, ability refers first of all to the administrative, political and financial authority of local governments and their autonomy in exercising these in key policy sectors. Research has found that municipalities that have specific competences for the direct provision of services like waste, transport and energy can have significant capacity and make use of it to address climate change (Bulkeley and Kern, 2006; Bai, 2007). It would, however, be too partial to look at local actors alone. Climate change adaptation is a multi-level concern, and the extent to which national and regional governments have actively supported urban actions also matters.

A second resource to formulate responses to climate change at city level is local knowledge. Research findings show that local action is driven by locally relevant scientific information. The identification of risks by downscaling climate models and the analysis of vulnerability generate political interest in understanding how the local climate is likely to change, how the city will be affected and what local response options seem appropriate to confront predicted impacts. In the attempt to address existing uncertainties about climate change impacts, there is significant reliance on university scholars, centres and programmes. Downscaling climate models and vulnerability analysis not only helps to identify threats but also encourages cities to establish priorities.

A third resource that affects the ability of local governments to engage in climate action is the presence of networks. They have been found to be successful in enrolling and keeping members inasmuch as they can offer expertise, funding opportunities and the ability to provide access to good practice (Kern and Bulkeley, 2009). For example, Cape Town has successfully implemented GHG mitigation measures through cooperation with external institutions including the Cities for Climate Protection (CCP) Programme of International Council for Local Environmental Initiatives (ICLEI) (Holgate, 2007). For Mexico the presence of influential scientists and the CCP network was instrumental in establishing climate change on the agenda (Romero Lankao, 2007). The transfer of ideas, knowledge and insight through external networks - i.e. of international or cross-country cooperation, such as the ICLEI, C40 Cities and United Cities and Local Governments (UCLG) - is strong, particularly across the very early adaptors. Membership in networks and attendance at conferences go beyond enhancing reputation, as these relationships and events are important sources of ideas and information for cities (Carmin et al., 2009). Furthermore, early adapters use various types of climate-related events and structures, including 'internal' networks in cities, making it possible for information to be exchanged between politicians and departments as well as fostering participation in events at regional, national and international level. This involves a strong presence and engagement of NGOs and CBOs.

Finally, an important resource in local climate action is the ability of municipal actors to reframe the issue as a local problem that also offers co-benefits. As demonstrated in this symposium, Santiago (Chile) and Delhi (India) are cases where actions to reduce GHG emissions are strongly connected with the goal of improved air quality, cost savings or the generation of additional finance. Thus, the ability to 'bundle issues' is regarded as a success factor (Koehn, 2009). Similarly, adaptation plans often adopt a twofold approach: they develop a general strategy that is then translated into sectorspecific goals and plans. The example of Quito (Carmin et al., 2009) shows that these strategies are not developed separately from other local development objectives but are tied closely to existing strategies. On the one hand, this ensures the integration and 'mainstreaming' of adaptation action. On the other, it serves as an opportunity to advance 
existing (local) development goals, and thus ensures continuity instead of radical change in local priorities. The focus, however, seems to vary significantly between cases. In some places, adaptation is connected strongly to existing environmental programs. In others, it supports the aim of building up reputation in order to create competitive advantage, for example in tourism.

The second aspect that drives and explains local action is willingness. Willingness covers the range of motivational factors that prompt local actors to act. For example, studies show that direct experience of extreme events/disasters is a strongly motivating factor (Bulkeley, 2010). The safety of the population and minimizing the impacts of natural disasters are also a strong trigger for action; they are major objectives found in adaptation plans (Carmin et al., 2009).

Related to this, early adaptation action involves strong local leadership that is motivated by an opportunity to become recognized as innovative and future-oriented. Such local championship relies on scientific knowledge and seizes opportunities for visibility in the regional, national and international arenas (Mukheibir and Ziervogel, 2007). It is often exemplified by people at the interface of science and policy who transmit scientific knowledge to regional politicians and stakeholders. Opportunities arise through networks that offer soft rewards for pioneering actions and trigger events, such as the hosting of global conferences (Kern and Bulkeley, 2009). In addition, the rising international recognition of the importance of climate action provides political backing to local initiatives. The city of Cape Town is an example, where the international climate agenda has helped the local government to implement projects that correspond to its own local sustainability agenda (Mukheibir and Ziervogel, 2007).

The third set of influence factors is connected with the societal frame conditions in a locality. The general political preferences of citizens and social acceptance of climate action and its implications can play a favourable or constraining role with regard to local climate action. For example, a study of the US found that climate action is most likely to be prioritized in communities that are most likely to be affected by the impacts of climate change and those with a liberal political constituency (Zahran et al., 2008).

In sum, regional differences in the combination of ability, willingness and societal frame conditions can explain differences in the intensity and nature of responses across nations and cities. As a result, wealthier nations and cities tend to have higher adaptive capacity while, conversely, cities in low- and middle-income nations are reported to have significantly lower capacity. While this position may serve as a first approximation to explain differences in local action, it is inadequate to illustrate why (although to a lesser extent, perhaps) less capable and resourceful cities have nevertheless managed to start action. In this symposium, we ask what actually drives or inhibits action in each of the case studies presented below. In concrete terms: what sets of capacities are 'employed'?

\section{Turning to the case cities}

The symposium focuses on a selection of cities in the global South — areas that are beginning to attract attention in the urban adaptation literature. It seeks to get a better grasp of commonalities and differences that exist with respect to stresses, their impacts, consequences, vulnerabilities, institutions, social and market actors, and urban responses - with a particular interest in adaptation. We acknowledge that the three selected cities have different characteristics, different urban experiences, different priorities, timelines and actor networks. We intend to sharpen the practice-oriented understanding of the role of cities in adaptation and 'likely' responses to climate change. In this sense we intend to explore the utility of the existing concepts - in particular those of ecological security and vulnerability - in assisting this generalization.

The selected case cities or city regions are Bogotá, Delhi and Santiago de Chile. There are three primary reasons for their selection: (1) to ensure diversity and balance of cases 
across continents; (2) to offer diversity and variety in aspects such as climatic conditions and governance structure through the richness of these cases with respect to adaptation; and (3) to take advantage of data accessibility. At the same time, the three cases highlight the critical role relationship of climate change and sensitive resources, which allowed us to 'test' the different approaches of ecological security and vulnerability. Finally, all cities are large urban agglomerations that can be expected to play an emblematic role in advancing the adaptation agenda in developing regions.

A common structure guided each author in writing the individual articles:

- Adaptation to what? Climate characteristics, sensitivity of the exposed system across temporal and spatial scales, anticipated impacts and local reinforcing factors.

- Who or what adapts? Lead actor, participants, coordination mechanisms, participation.

- How does adaptation occur? Motivated action, policy fields where dedicated action was introduced, type of action, role of information, knowledge basis, implementation/ compliance/monitoring, financing, organizational arrangements.

- On what basis does adaptation occur? Capacities, assets, resources and characteristics of agency that matter most.

Andrea Lampis (2013, this issue), in his article on Bogotá, discusses the significant challenges of adaptation action in the Colombian capital. The author focuses on two key issues and relevant entry points for an analysis of the complex interaction between city-level institutions, climate change and adaptation. First, he deals with the lack of cross-sector and inter-agency institutions. A multi-scale, multi-level and interdisciplinary challenge such as climate change cannot be successfully faced by a single organization or body. Second, he discusses the challenge represented by the capacity to improve public policies relating to key areas of public services provision as well as to access to, and the creation of, collective capital. The author brings the concept of policy styles closer to the debate on adaptation and applies it to the case study of Bogotá. A policy style defines the way policies are traditionally implemented in countries and cities; he argues that it should be considered as one of the key factors for understanding why institutions are promoting or slowing down adaptation to climate change in cities. Unfortunately, ecological security and social vulnerability are entirely absent from the Environmental Secretariat of the Capital District's policy horizon. Interestingly, considering the anticipation-reaction criteria set in the UES conceptual framework, this urban institution - the one most directly connected with the process of GEC - scores rather low in terms of climate change adaptation policies.

In her article on Delhi, Rimjhim Aggarwal (2013, this issue) points out a set of features that make the city a particularly interesting case. Delhi is an 'early adapter' and part of the motivation for this has been the linking of material and ecological security with the competitive positioning of cities as emphasized in the UES literature. Closely following the National Action Plan of 2008, the administration of the National Capital Territory (NCT) adopted its own legislation in 2009. This was largely driven by strategic considerations to ensure access to mitigation-financing mechanisms for urban development projects. Likewise interesting and unique for India is that the Urban Local Bodies, the lowest administrative units in the NCT, enjoy a far greater degree of fiscal, administrative authority than those in the rest of the country. Located in a subtropical climate with seasonal monsoon, Delhi's climate change projections present a mixed image. What is somewhat clearer is that climate change and its potential effects are linked to an endogenous factor, namely rapid population growth in the suburban towns along the Yamuna River. This adds to already existing inequalities and vulnerabilities as Delhi is expected to face major stress on water availability. Connecting the case study with the UES framework, Aggarwal points out that the local climate action plan was not drawn up with the aim of ensuring ecological security for water resources in mind. Rather, it has been used to demonstrate international 'leadership' and to capture the opportunity to advance an existing development agenda (basic service provision) 
through strategically accessing financial instruments (such as the Clean Development Mechanism). She also finds that the short time horizon of related policies directly conflicts with the idea of development of anticipatory and preparatory strategies for the reconfiguration of urban infrastructures. In short, motivations for local climate action in Delhi prove to be a mixed bag within the context of UES and vulnerability.

In his contribution on Santiago de Chile, Jonathan Barton (2013, this issue) explores the linkages between climate change adaptation and spatial planning. Projected data for possible future impacts of climate change on the metropolitan region suggest an increase in the median temperature of around $3-4^{\circ} \mathrm{C}$ (in parts to $5^{\circ} \mathrm{C}$ ) for the period $2071-2100$. In terms of precipitation (scenarios A2 and B2), the reductions are in the order of $40 \%$. The principal glaciers that feed the basin's two river systems are likely to contract in accordance with expected changes in temperature and precipitation. These changes are directly connected with water supply and energy use in the metropolitan region, which again is linked to the size of its population, which is expected to grow from a current 6 million to 8 million by 2020 . The challenges of water and energy scarcity interact with changing land cover and land uses that bring increased risks (e.g. of episodic floods). With the current formulation of the national agenda for climate change, the National Government is the main actor and is from 'outside' the city. This helps to explain the type of approach, which is still not set to respond to the challenges adequately as adaptation is only rarely considered and mostly related to exposed systems and sectors, no explicit urban focus being given. This means that only if issues such as water and energy planning and the reduction of vulnerability are conceptualized as development concerns can they be fully integrated into the existing metropolitan governance structure. Climate change adaptation is not yet, therefore, in the local regional agenda, but should be understood as part of current planning frameworks rather than a specific sectoral need that could be managed by a single agency or via specific instruments such as a unitary action plan. As regards flood protection, for example, unlike large cities in the global North, Santiago de Chile is not undertaking city-wide public infrastructure measures as a strategic protection. Ecological security in this regard is not at the forefront of the political agenda. Poorer and better-off segments of the population are equally exposed to environmental hazards. What distinguishes different socioeconomic groups is their individual adaptive capacity to protect themselves from the effects of climate change. The institutional challenges that need to be overcome relate to human capital building, financing instruments and a cross-sectional approach to local action. One of the biggest challenges to climate governance is the capacity to overcome the sectoral divisions and disconnects, as, for example, between energy and water policy.

\section{Discussion}

The bidirectional interactions between urban areas and climate change have fostered an impressive array of responses in urban areas during the last few years. A review of those responses shows diverse international, regional, national and local initiatives. A significant number of them have been created in large cities in industrialized countries. This symposium highlights how cities in the global South have likewise begun taking action. The articles selected explore a set of case studies of urban regions that confront their projected climate change challenges and address knowledge gaps on a variety of climate change response questions.

The first question is, whether the cases highlight new pathways through which urban governance can better address the problem of climate change. The cases show that urban social responses to climate change rest on a wide range of policies that primarily seek to materialize the opportunities for enhancing local capacities and realizing co-benefits. For example, the authorities in Delhi link climate change action to 'image building' and, with the focus on the Clean Development Mechanism (CDM), intend to realize both economic 
and ecological benefits. The case study is an account of the rather pragmatic, project-focused and short-term approach pursued in this strategy.

These insights are useful for understanding the adaptation challenges that cities face and the key capacities that they require. For all cases, the challenges ahead are related to adopting a long-term orientation on adaptation and involving the population in general (a weakness of the Delhi Plan) and concerned stakeholders in particular. The current short-term focus stands in the way of analysing and identifying the more strategic long-term priorities and strategies and aggregating the required capacities. This includes challenges like building longer-term financing instruments (multi-year budgets), overcoming sectoral divisions and mainstreaming climate change into existing regulation (like land use plans).

The second question relates to adaptation challenges that cities face across the world and current practices of urban adaptation. The combination of existing capacities highlighted in the cases reflects the range of capacities outlined in the section 'Urban responses to climate change' above. Very important is the specific motivation attached to embarking on (or refraining from) climate policies. Delhi officials adopted their action with the intention of achieving complementary goals. However, the motivation and capacities are, in the end, a context-specific issue and difficult to generalize. What seems of overriding significance, and perhaps has not received enough attention so far, is the importance of building and aggregating the commitment and cooperation of various actors at and across different levels (horizontally and vertically). It seems important that city-level action is complemented by action at national level (and vice versa). The cases make evident that local climate action relies on both a strong leading actor and other key agents who contribute their own capacities. Thus, any attempt at local climate action builds on identifying and aggregating joint and common interests. This not only explains action in a positive sense, as in the case of Delhi where national and metropolitan interests and actions complement each other, it also explains negative experiences, as in Chile, where the absence of capacities at the regional level and a lack of willingness in the local mayor's offices represent major obstacles to national action reaching down to the local level.

The third question is whether the outlined conceptual frameworks provide a useful framing for local action. The cases show that each of the concepts takes up vital aspects of the challenges and responses faced locally, for example, the prominent role of networks (all cases), or awareness of scarce resources (Delhi, Bogotá). The natural science perspective and framing, shown by the existence and use of climate change model data is evident in all cases, although it has less visibility in shaping policy in Delhi. In the case of Bogotá, policy builds on evidence of existing risks and vulnerabilities.

The concept of ecological security is particularly valuable because it highlights the long-term perspective. However, as shown in the Delhi case, it is perhaps the most difficult to put into practice - in particular in the global South where cities have to address pressing concerns of the 'here and now'. These are more related to the concept of 'contextual vulnerability' and to the challenge of resolving apparent development deficits. Across cases, the evidence suggests that concepts are needed that pay much more attention to the 'political economy' behind action and, related to this, to motivational factors, to cooperation, multi-level governance, and to understanding the 'policy styles' and the 'traditional ways' in which policies are implemented.

Fourth and finally, the symposium raises the questions of how the future viability of current actions or plans can be judged through these conceptual frameworks and how we can evaluate current practice through the lenses of individual conceptual frameworks. The cases explored in this symposium suggest that the concepts, when geared to the local context, are useful not only for explaining action but also for evaluating it. However, each concept has its own particular strength and focus. The ecological security concept introduces a long-term perspective on human-environment interaction and human security. It is particularly useful in building joint understanding and interest in designing longer-term action programmes in key policy fields, such as addressing the energy-water 
nexus in Santiago de Chile. It also uncovers the weaknesses of current approaches. As shown in all cases, such long-term commitment is perhaps most lacking in current climate adaptation. The contextual vulnerability approach emphasizes equity concerns and inclusiveness, a factor that must not be neglected in cities in the global South. The focus on outcome vulnerability stresses the role of a natural science base and evidence in supporting informed action. It relates to ecological security as it highlights critical long-term trends. To this extent then, each of the different conceptual frameworks contributes a vital perspective and broad criteria for the evaluation of particular responses to climate change. They are, however, not sufficient to assess or explain their success. From the cases presented in this symposium, understanding and considering locationspecific capacities seems a promising way to move forward in this direction.

Dirk Heinrichs (dirk.heinrichs@dlr.de), Institute of Transport Research, German Aerospace Center, Rutherfordstr. 2, Berlin 12489, Germany, Kerstin Krellenberg (kerstin.krellenberg@ufz.de), Helmholtz Centre for Environmental Research, Urban and Environmental Sociology, Permoser Str. 15, Leipzig 04318, Germany and Michail Fragkias (michailfragkias@boisestate.edu), Boise State University, 1910 University Drive, Boise, ID 83725, USA.

\section{References}

Adger, N., T.P. Hughes, C. Folke, S.R. Carpenter and J. Rocksrom (2005) Socio-ecological resilience to coastal disasters. Science 309.5737, 1036-39.

Aggarwal, R. (2013) Strategic bundling of development policies with adaptation: an examination of Delhi's Climate Change Action Plan. International Journal of Urban and Regional Research 37.6, 1902-15.

Allen, R. (ed.) (2002) The Penguin concise English dictionary. Penguin, London.

Bai, X. (2007) Integrating global environmental concerns into urban management: the scale and readiness arguments. Journal of Industrial Ecology 11, 15-29.

Barton, J. (2013) Climate change adaptive capacity in Santiago de Chile: creating a governance regime for sustainability planning. International Journal of Urban and Regional Research 37.6, 1916-33.

Berrang-Ford, L., J.D. Ford and J. Paterson (2010) Are we adapting to climate change? Global Environmental Change [WWW document]. URL http://resilient-cities .iclei.org/fileadmin/sites/resilient-cities/ files/Images_and_logos/Resilience_ Resource_Point/Ford_Paterson_Are_ we_adapting_to_climate_change.pdf (accessed 14 January 2013).

Bollin, C. and R. Hidajat (2006) Community-based disaster risk index: pilot implementation in Indonesia. In J. Birkmann (ed.), Measuring vulnerability to natural hazards: towards disaster resilient societies, United Nations University Press, New York.

Bulkeley, H. (2010) Cities and the governing of climate change. Annual Review of Environment and Resources 35.2, 229-53.

Bulkeley, H. and K. Kern (2006) Local government and climate change governance in the UK and Germany. Urban Studies 43, 2237-59.

Burch, S. and J. Robinson (2007) A framework for explaining the links between capacity and action in response to global climate change. Climate Policy 7.4, 314-16.

Carmin, J.A., D. Roberts and I. Anguelowski (2009) Planning climate resilient cities. Early lessons from early adapters. Paper presented at the fifth Urban Research Symposium - Cities and Climate Change: Responding to an Urgent Research Agenda, Marseille, France, June 28-30 [WWW document]. URL http:// siteresources.worldbank.org/ INTURBANDEVELOPMENT/ Resources/336387-1256566800920/ 6505269-1268260567624/Carmin.pdf (accessed 16 January 2013).

Chambers, R. (ed.) (1989) Vulnerability. How the poor cope. IDS, Brighton.

de Sherbinin, A., A. Schiller and A. Pulsipher (2007) The vulnerability of global cities to climate hazards. Environment and Urbanization 19.1, 39-64. 
Haddad, B. (2005) Ranking the adaptive capacity of nations to climate change when socio-political goals are explicit. Global Environmental Change 15.3, 199-213.

Hodson, M. and S. Marvin (2009) Urban ecological security: a new urban paradigm? International Journal of Urban and Regional Research 33.1, 193-215.

Holgate, C. (2007) Factors and actors in climate change mitigation: a tale of two South African cities. Local Environment: The International Journal of Justice and Sustainability 12.5, 471-84.

IPCC (Intergovernmental Panel on Climate Change) (2001) Climate change 2001: impacts, adaptation and vulnerability. Contribution of Working Group II to the Third Assessment Report of the Intergovernmental Panel on Climate Change (IPCC). Cambridge University Press, Cambridge UK and New York.

IPCC (2007a) Climate change 2007: Synthesis Report. IPCC, Geneva.

IPCC (2007b) Climate change 2007: impacts, adaptation and vulnerability. Contribution of Working Group II to the Fourth Assessment Report of the IPCC. IPCC, Geneva.

Kelly, P.M. and W.N. Adger (2000) Theory and practice in assessing vulnerability to climate change and facilitating adaptation, Climatic Change 47, 325-52.

Kern, K. and H. Bulkeley (2009) Cities, Europeanization and multi-level governance: governing climate change through transnational municipal networks. Journal of Common Market Studies 47.2, 309-32.

Klein, R., L. Schipper and S. Dessai (2007) Integration, mitigation and adaptation into climate and development policy: three research questions. Working Paper 40, Tyndall Centre for Climate Change Research, Norwich.

Koehn, P.H. (2009) Underneath Kyoto: emerging subnational government initiatives and incipient issue-bundling opportunities in China and the United States. Global Environmental Politics 8, 53-77.

Lampis, A. (2013) Cities and climate change challenges: institutions, policy style and adaptation capacity in Bogotá. International Journal of Urban and Regional Research 37.6, 1879-901.

McCarney, P. (2009) City indicators on climate change: implications for policy leverages and governance. Paper presented at the, $5^{\text {th }}$ Urban Research Symposium Cities and Climate Change: Responding to an Urgent Research Agenda, Marseille, France, June 28-30 [WWW document]. URL http://siteresources.worldbank.org/ INTURBANDEVELOPMENT/Resources/ 336387-1256566800920/6505269 -1268260567624/McCarney.pdf (accessed 16 January 2013).

Mukheibir, P. and G. Ziervogel (2007) Developing a municipal adaptation plan (MAP) for climate change: the city of Cape Town. Environment and Urbanization 19.1, 143-58.

O'Brien, K., S. Eriksen, L. Nygaard and A. Schjolden (2007) Why different interpretations of vulnerability matter in climate change discourses. Climate Policy 7, 73-88.

Pirages, D. (1997) Demographic change and ecological security. Wilson Center [WWW document]. URL http://www. wilsoncenter.org/sites/default/files/ ACF14AC.pdf (accessed 16 January 2013).

Rogers, K.S. (1997) Ecological security and multinational corporations. Environmental Change and Security Project (ECSP) report [WWW document]. URL http:// www.isn.ethz.ch/isn/Digital-Library/ Publications/Detail/?ots591=cab359a3 -9328-19cc-a1d2-8023e646b22c\&lng $=$ en $\& i d=136188$ (accessed 16 January 2013).

Romero Lankao, P. (2007) How do local governments in Mexico manage global warming? Local Environment 12.5, 519-35.

Sánchez-Rodríguez, R., K. Seto, D. Simon, W.D. Solecki, F. Kraas and G. Laumann (eds.) (2005) Science plan urbanization and global environmental change. International Human Dimensions Programme on Global Environmental Change, Bonn.

Sen, A. (1992) Inequality re-examined. Clarendon Press, Oxford.

Seto, K.C., R. Sanchez-Rodriguez and M. Fragkias (2010) The new geography of contemporary urbanization and the environment. Annual Review of Environment and Resources 35, 167-94.

Simon, D. (2007) Cities and global environmental change: exploring the links. The Geographical Journal 173.1, 75-9. 
Smit, B., I. Burton, R. Klein and J. Wandel (2000) An anatomy of adaptation to climate change and variability. Climate Change 45, 223-51.

Smit, B. and J. Wandel (2006) Adaptation, adaptive capacity and vulnerability. Global Environmental Change 16, 282-92.

Solomon S., G.-K. Plattner, R. Knutti and P. Friedlingstein (2009) Irreversible climate change due to carbon dioxide emissions. Proceedings of the National Academy of Science of the United States of America doi:10.1073/pnas.0812721106.

Tompkins, E. and N. Adger (2005) Defining response capacity to enhance climate change policy. Environmental Science and Policy 8.6, 562-71.

UN Population Division (2008) World urbanization prospects. The 2007 revision. United Nations, New York.

United Nations Environment Programme (UNEP) (2007) Global environment outlook 4 (GEO-4): environment for development. UNEP, Nairobi.
UN/ISDR (2006) Hyogo framework for action 2005-2015. UN/ISDR, Geneva [WWW document]. URL http://www. unisdr.org (accessed 18 February 2010).

Vitousek, P.M. (1992) Global environmental change: an introduction. Annual Review of Ecology and Systematics 23, 1-14.

WBGU (German Advisory Council on Global Change) (2008) Climate change as a security risk. Flagship Report. Earthscan, London.

Wisner, B., P. Blaikie, T. Cannon and I. Davies (2004) At risk: natural hazards, people's vulnerability, and disaster. Routledge, London.

Yohe, G. (2001) Mitigative capacity: the mirror image of adaptive capacity on the emission side. Climate Change 49.3, 247-62.

Zahran, S., S.D. Brody, A. Vedlitz, H. Grover and C. Miller (2008) Vulnerability and capacity: explaining local commitment to climate change policy. Environment and Planning C 26, 544-62. 